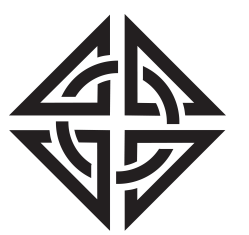

SCIENTIA
Sharif University of Technology

Scientia Iranica

Transactions A: Civil Engineering

http://scientiairanica.sharif.edu

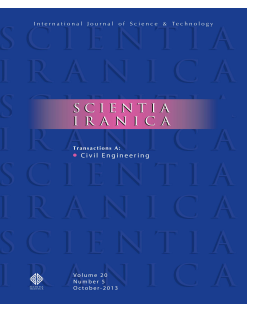

\title{
Experimental study of the effect of water to cement ratio on mechanical properties and durability of nano-silica concretes with polypropylene fibers
}

\author{
K. Rahmani ${ }^{\mathrm{a}}$, M. Ghaemian ${ }^{\mathrm{b}, *}$, and S.A. Hosseini ${ }^{\mathrm{a}}$ \\ a. Department of Civil Engineering, Science and Research Branch, Islamic Azad University, Tehran, Iran. \\ b. Department of Civil Engineering, Sharif University of Technology, Tehran, Iran. \\ Received 26 August 2017; received in revised form 20 November 2017; accepted 24 December 2017
}

\author{
KEYWORDS \\ Concrete; \\ Nano-silica; \\ Polypropylene fiber; \\ Mechanical properties \\ of concrete; \\ ASTM standard.
}

\begin{abstract}
This study investigates the effect of nano-silica on mechanical properties and durability of concrete containing polypropylene fibers. Herein, the length and the length-to-diameter ratio of used polypropylene fibers were considered fixed and equal to $18 \mathrm{~mm}$ and 600, respectively, and the cement content was $479 \mathrm{~kg} / \mathrm{m}^{3}$. The effects of fibers and nano-silica in four different percentages of $0.1,0.2,0.3$, and $0.4 \%$ volume for fibers and $3 \%$ for nano-silica in concrete with water to cement ratios of $0.33,0.36$, $0.4,0.44$, and $0.5 \%$ were compared and evaluated. In total, more than 425 cubic and cylindrical specimens were made according to ASTM standards. Finally, samples of polypropylene fiber containing nano-silica were tested under compressive loads, flexural strength, indirect tensile strength (Brazilian test), abrasion resistance, permeability, and porosity; in addition, their mechanical properties were evaluated. The test results showed a significant improvement of mechanical properties and durability of concrete. Compressive strength, tensile strength, flexural strength, and abrasion resistance (of concrete) increased by $55 \%, 25 \%, 49 \%$, and $45 \%$, respectively. In addition, a considerable reduction in hydraulic conductivity coefficient by $50 \%$ indicates the high durability of these types of concrete.
\end{abstract}

(C) 2019 Sharif University of Technology. All rights reserved.

\section{Introduction}

The use of various additives in concrete and cement products has attracted considerable attention in recent years. So far, many research studies have been carried out on fiber concrete; however, very few studies have been devoted to the nano-silica concrete containing polypropylene fibers. Particularly, the effect of nano-

\footnotetext{
*. Corresponding author.

E-mail addresses: k.rahmani@iau-mahabad.ac.ir (K.

Rahmani); ghaemian@sharif.edu (M. Ghaemian);

abbas_hoseyni@srbiau.ac.ir (S.A.Hosseini)
}

doi: $10.24200 /$ sci.2017.5077.1079 silica on fiber concrete, especially polypropylene fibers, has been scarcely investigated.

To this end, the use of fiber concrete, especially polypropylene fibers with nano-silica, was considered in this study. High-Strength Fiber Reinforced Concrete (HSFRC) has a wide range of applications in which different types of fibers are used to increase the toughness, flexibility, and tensile and flexural strength of the concrete in order to increase the strength of structural members under static and dynamic loads and to reduce cracking and crushing [1].

Polypropylene fiber was introduced in the mixture to minimize the brittleness of the matrix, thereby reducing the susceptibility to cracking of concrete [2]. It was also reported that polypropylene fiber was effective 
in resisting the development of cracks caused by drying shrinkage [3]. The inclusion of polypropylene fiber in concrete showed excellent durability on exposure to freeze-thaw cycling [4].

Studies have indicated that the explosive spalling of regular High-Strength Concrete (HSC) could be noticeably alleviated by embedding an appropriate volume of strong, flexile polypropylene fibers $[5,6]$. This improvement is supposedly attributed to the difference of the thermal expansion capability between polypropylene fibers and cement pastes, which can introduce micro-fractures to release the vapor pressure $[7,8]$.

Experimental research and analytical study by Olivito and Zuccarello [9] provided reinforced concrete with steel fiber with mixing patterns and different lengths of different fibers. They evaluated compressive and tensile strengths, fracture, and ductility. The addition of fibers increased the ductility, which is associated with energy absorption during fracture. Samples of longer fibers showed higher strain as compared to the samples with shorter fibers.

Zhang and $\mathrm{Li}$ [10] performed an experimental study to investigate the combined effect of silica fume and polypropylene fiber on the workability and drying shrinkage of concrete composite containing fly ash. They concluded that the workability of the concrete composite improved, and the drying shrinkage strain decreased gradually with the increase of fly ash content. However, polypropylene fiber has an inconsiderable adverse effect on the workability of concrete composite.

Authors [11-13] showed that the behavior of concrete at high temperatures could be improved by adding polypropylene fibers (with a ratio varying from $\left.0.5 \mathrm{~kg} / \mathrm{m}^{3}-3 \mathrm{~kg} / \mathrm{m}^{3}\right)$. The melting $\left(160^{\circ} \mathrm{C}-170^{\circ} \mathrm{C}\right)$ and vaporization $\left(350^{\circ} \mathrm{C}\right)$ of polypropylene fibers generate not only new pores, but also create microcracks at the tip of fibers connecting the already existing pores [14]. Ozawa and Morimoto [15] carried out permeability tests on high strength concretes (72 $\mathrm{MPa}$ ) including $0.15 \%$ of volume of PPF. Results showed that the residual permeability increased 12 times after heating the PPF concrete to $500^{\circ} \mathrm{C}$, compared to the referenced concrete. Thus, the improvement of permeability reduces the likelihood of explosive spalling [16].

Consoli et al. [17] showed that the reinforcing effect of polypropylene fibers became less effective in high cement contents for a stabilized sandy soil, i.e., the peak strength only increased until $4 \%$ of cement content and, after that, the effect of the fiber reinforcement had the opposite effect. In fact, when the cement content is high, the stiffness of the stabilized soil is fundamentally governed by the high stiffness of the cement, and the polypropylene fibers are, therefore, unable to mobilize the tensile strength before peak failure, since the deformations obtained are very low. Thus, increasing the amount of fiber for high cement contents does not have repercussions on the increase of the strength [17]. Thus, polypropylene fiber, carbon fiber, plastic-glass-based fiber, and steel fibers started to be used in concrete. It is known that steel, nylon, and mixed fibers insignificantly affect mechanical properties (e.g., compressive strength and elasticity module) and highly increase the mechanical properties (bendingtensile strength, ductility, and toughness) $[18,19]$.

It is well understood that silica fume, due to high pozzolanic activity, is a necessary material when producing high-strength concrete. Silica fume effectively improves the structure of the transition zone, eliminates the weakness of the interfacial zone, reduces the number and size of cracks, and enhances the ability of steel fiber to resist cracking and restrain damage. Both normal-strength concrete and high-strength concrete are brittle, with a degree of brittleness increasing with increasing strength [20].

Nili and Afroughsabet [21] showed that the silica fume improved the compressive strength of the concretes with higher ages by improving the conjunction of aggregates with cement paste. In addition, the simultaneous use of silica soot and fiber in concrete mixtures results in an effective increase in the flexural strength of concrete.

Pore structure parameters, such as porosity, pore size distribution, etc., are progressively employed to evaluate permeability, frost resistance, carbonation resistance, and physical strength of concrete [22-24].

Tijani et al. [25] added artificial carbon fiber and microsilica to some concrete mixtures to improve their mechanical properties. Maslennikov et al. [26] analyzed the effect of different modifiers on the properties of concrete mixtures using microsilicon additive.

Subramanian et al. [27] showed that nano-silica and micro-silica could be successfully used in the preparation of Self-Compacting Concrete (SCC).

Khanzadi et al. [28] measured compressive strength, tensile strength, and water absorption percentage and chloride penetration depth in concrete containing nano-silica. They showed that the measured mechanical properties and the durability of the concrete mixed with the nano particles were better than those of a plain concrete were.

In recent years, using different additives in concrete and cement products have attracted considerable attention. Fiber and nano-silica concrete can be considered as the most commonly used additives. In this study, by reviewing the advantages of using nanosilica and polypropylene fibers in concrete, 450 sample concretes were prepared using 20 mixture designs with water to cement ratios of $0.33,0.36,0.4,0.44$, 0.5 , fiber volume ratios of $0.1,0.2,0.3,0.4$, and $3 \%$ volume of nano-silica based on ACI and ASTM standards. The purpose of the present study is three- 
fold: to determine the effect of polypropylene and nano-silica fibers on behavioral properties of concrete under stress conditions due to flexural loads, to study the permeability and porosity of the concrete, and to obtain their optimal percentage. In this research, the length of polypropylene fiber is considered $18 \mathrm{~mm}$. Eventually, compressive strength, flexural strength, tensile strength, abrasion resistance, permeability, and porosity tests conducted on the samples containing nano-silica and their mechanical properties are investigated.

\section{Experiments performed on samples}

In the present study, the concrete samples with $3 \%$ nano-silica and water to cement ratios of $0.33,0.36$, $0.4,0.44,0.5$ and fiber contents of $0,0.1,0.2,0.3$ of concrete volume are investigated experimentally:

- The cement used in these experiments is of ordinary Portland cement (ASTM Type I) in accordance with Table 1;

- For all samples, the amount of fixed nano-silica and $3 \%$ consumption cement are replaced, as shown in Table 2;

- The amount of polypropylene fiber varies and is equal to $0,0.1,0.2$, and 0.3 volumetric percent alternatives of the cement used; The properties of the consumed polypropylene fiber are shown in Table 3 , and its mixture design with the nano-silica is shown in Table 4;

Table 1. Properties of ordinary Portland cement (ASTM Type I) used in the present tests.

\begin{tabular}{clc}
\hline No. & Property of cement & Value \\
\hline 1 & Normal consistency & $31 \%$ \\
2 & Initial setting time & $120 \mathrm{~min}$ \\
3 & Final setting time & 6 hour \\
4 & Specific gravity & 3.11 \\
5 & Compressive strength of & $55.6 \mathrm{MPa}$ \\
\hline
\end{tabular}

Table 2. Properties of nano-silica [29].

\begin{tabular}{lc}
\hline \multicolumn{1}{c}{ SI. no } & Dispersed in water \\
\hline Active nano content $(\%)$ & $40-41.5$ \\
$\mathrm{Ph}\left(20^{\circ} \mathrm{C}\right)$ & $9-10$ \\
Specific gravity & 1.4 \\
Particle size & $10-40 \mathrm{~nm}$ \\
\hline
\end{tabular}

Table 3. Properties of polypropylene fiber [29].

\begin{tabular}{lc}
\hline \multicolumn{1}{c}{ Properties } & Value \\
\hline Density $\left(\mathrm{kg} / \mathrm{m}^{3}\right)$ & 900 \\
Reaction with water & Hydrophobic \\
Tensile strength $(\mathrm{MPa})$ & $300-400$ \\
Melting point $\left({ }^{\circ} \mathrm{C}\right)$ & 175 \\
Length $(\mathrm{mm})$ & 18 \\
\hline
\end{tabular}

- Compressive strength of the 28-day specimen is $40 \mathrm{MPa}$;

- The maximum diameter of aggregates is $15 \mathrm{~mm}$. Table 5 summarizes the properties of required materials for a samples design. Actually, this table shows the concrete mixture design proportions $\left(\mathrm{kg} / \mathrm{m}^{3}\right)$ used in the present study;

- Super lubricant used in these experiments is super plasticizer 400 according to ASTM-C494 Type 4 standard.

In the production of test specimens, excess water was computed and added to the dry state (S.S.D state) to prevent the free water absorption of the concrete into the empty space of the aggregate;

- A flexural strength test was carried out on concrete beams of $10 \times 10 \times 50 \mathrm{~cm}$ on the 28 th day. All stages of testing were performed according to ASTM-C1018 standard. Eq. (1) can be used in order to calculate the flexural strength [30]:

$$
\text { Flexural strength }=\left[\left(P L / b d^{2}\right) \times 1000\right] .
$$

In the above equation, $P, L, b$, and $d$ are the applied load at fracture moment, the length of the specimen, the section's width, and the section's height, respectively;

- An indirect tensile strength test or tensile strength of halving is performed on cylindrical specimens of $300 \times 150 \mathrm{~mm}$ on the 28 th day. To do so, the load needs to be done continuously and without impact. The load speed of $80 \mathrm{kN} / \mathrm{min}$ was selected according to the ASTM C496 standard. Eq. (2) illustrates how to determine tensile strength [31]:

Tensile strength $=[(2 P / \pi d L) \times 1000]$,

where $P$ is the applied load at the fracture moment; $L$ and $d$ are the length and diameter of the cylinder, respectively;

- Abrasion strength test on cube samples $150 \times 150 \times$ $150 \mathrm{~mm}$ on the $28 \mathrm{th}$ day was performed by the water sand blast method based on ASTM-C778 standard;

- The hydraulic conductivity of the concrete was tested by penetration method according to ASTMC1920-5 [32]:

Hydraulic conductivity $=H p^{2} V /(2 T H)$, 
Table 4. Nano-silica fiber concrete mixture designs.

\begin{tabular}{ccccc}
\hline $\begin{array}{c}\text { Mixing } \\
\text { scheme } \\
\text { number }\end{array}$ & $\begin{array}{c}\text { Polypropylene } \\
\text { fiber } \\
(\%)\end{array}$ & $\begin{array}{c}\text { Polypropylene } \\
\text { fiber content } \\
(\mathbf{k g})\end{array}$ & $\begin{array}{c}\text { Water } \\
\text { to cement } \\
\text { ratio }\end{array}$ & $\begin{array}{c}\text { Nano-silica } \\
\text { content } \\
(\mathbf{k g})\end{array}$ \\
\hline 1 & 0.1 & 0.56 & & \\
2 & 0.2 & 1.13 & 0.33 & 14 \\
3 & 0.3 & 1.7 & & \\
\hline
\end{tabular}

Table 5. Nano-silica fiber concrete mixture designs $\left(\mathrm{kg} / \mathrm{m}^{3}\right)$.

\begin{tabular}{lccccc}
\hline Water-to-cement ratio & 0.33 & 0.36 & 0.40 & 0.44 & 0.5 \\
Nano-silica weight (kg) & 14 & 14 & 14 & 14 & 14 \\
Cement weight (kg) & 465 & 465 & 465 & 465 & 465 \\
Water consumption (lit) & $158+20$ & $172+20$ & $191+20$ & $211+20$ & $239+20$ \\
Weight of coarse gravel (kg) & 470 & 470 & 470 & 470 & 470 \\
Weight of tiny gravel (kg) & 385 & 385 & 385 & 385 & 385 \\
Sand weight $\mathbf{( k g )}$ & 821 & 821 & 821 & 821 & 821 \\
\hline
\end{tabular}

where:

Hp Water penetration depth $(\mathrm{m})$;

$T \quad$ Influence time (sec);

$H \quad$ Pressure height $(\mathrm{m})$;

$V \quad$ Concrete porosity.

The following formula can be used to calculate the porosity of the concrete [33]:

Concrete porosity $=(w / c) \times(100-36.15 \alpha)$

$$
/(W+100 / g)
$$

where $w / c$ is the water to cement ratio, $\alpha$ is the cement hydration degree, $W$ is the pure water of concrete, $\mathrm{kg} / \mathrm{m}^{3}$, and $g$ is the cement specific weight, $\mathrm{gr} / \mathrm{cm}^{3}$;

- Compressive strength tests on cube samples of $150 \times$ $150 \times 150 \mathrm{~mm}$ on the $7 \mathrm{th}, 28 \mathrm{th}$, and 91 th days were done with a pressure test device with a capacity of $2000 \mathrm{kN}$ (Tekno test-Italy) at a speed of $2.5 \mathrm{kN} / \mathrm{S}$ in accordance to ACI-C330 standard. The compressive strength value of samples can be evaluated using Eq. (5):

Compressive strength $=[(P / A) \times 1000]$,

where $P$ is the applied load at fracture, and $A$ is the cross-sectional area of cubic samples.

\section{The mixture scheme of fiber concrete containing nano-silica}

In the mixture scheme of samples, the following points are considered:
- Slump test, according to the ACI, the 544 Committee, is not suitable for fiber concrete, and one needs to use the inverted slump test. The inverted slump for samples is achieved in the period of 8-12 seconds;

- The aggregates are broken.

\section{Analysis of the flexural strength test results}

According to Figure 1, it is shown that the flexural strength increases with the addition of fibers. As the graphs show, the addition of fibers up to $0.3 \%$ and $3 \%$ of nano-silica has a significant effect on flexural strength. However, the flexural strength decreases in higher fiber ratios. It is anticipated that by increasing the fiber content to more than $0.3 \%$, the flexural strength will be reduced. In this part, inappropriate distribution of fibers can also be affected. Non-fibrous

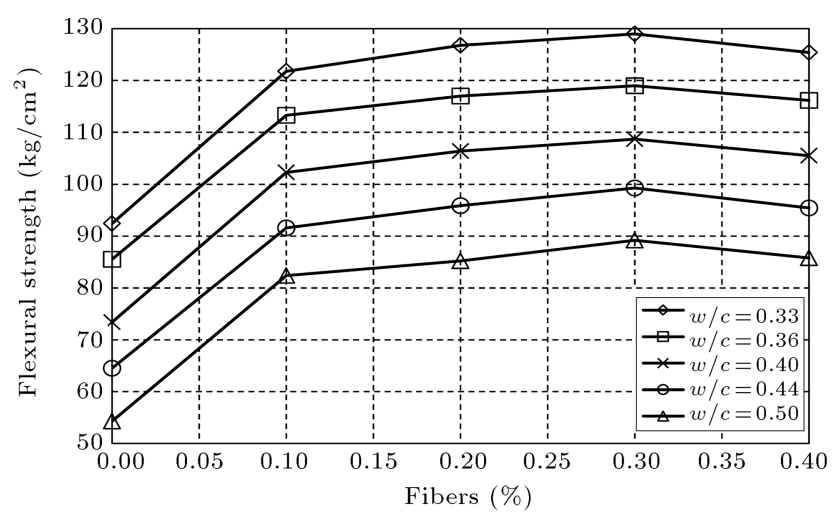

Figure 1. Flexural strength of the fiber-based samples for different water to cement ratios. 
samples are fractured during failure, where this problem is completely eliminated by the fiber. According to Figure 2, by decreasing the water to cement ratio from 0.50 to 0.3 in non-fiber samples, the flexural strength has improved by $70.17 \%$. In the water to cement ratio of 0.33 , by adding $0.1,0.2$, and $0.3 \%$ of the fibers to the samples, according to Figure 3, the flexural strength has improved by $31.81,37.23$, and $39.61 \%$, respectively.

\section{Analysis of the tensile strength test results}

Figure 4 illustrates that indirect tensile strength increases with the addition of polypropylene fibers. As shown in the diagram, by adding $0.1 \%$ fiber, there is a significant effect on tensile strengths. In the fiber ratio higher than $0.3 \%$, the tensile strength decreases. In addition, according to Figure 5, one can see that by reducing the water to cement ratio from 0.5 to 0.33 in concrete samples without fiber, the tensile strength has improved by $82.4 \%$. By adding $0.1,0.2$, and $0.3 \%$ fibers for the water to cement ratio of 0.33 ,

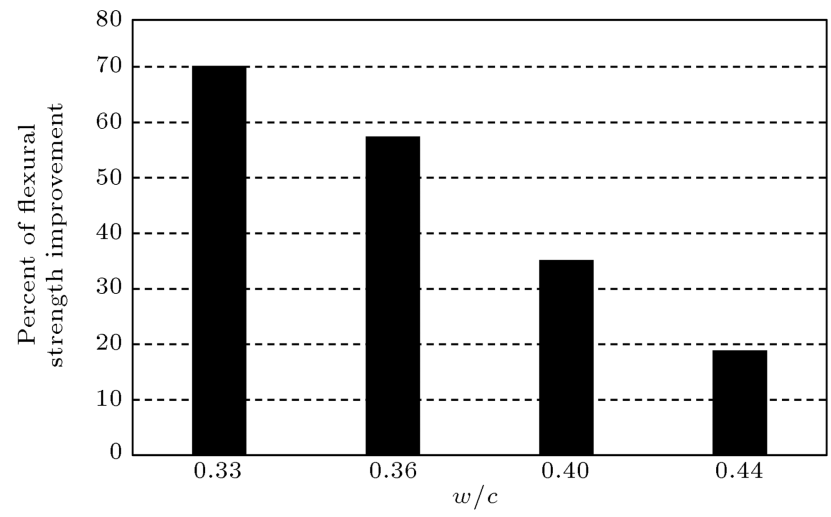

Figure 2. The percentage of improvement in flexural strength without fiber for water to cement ratio of 0.50 .

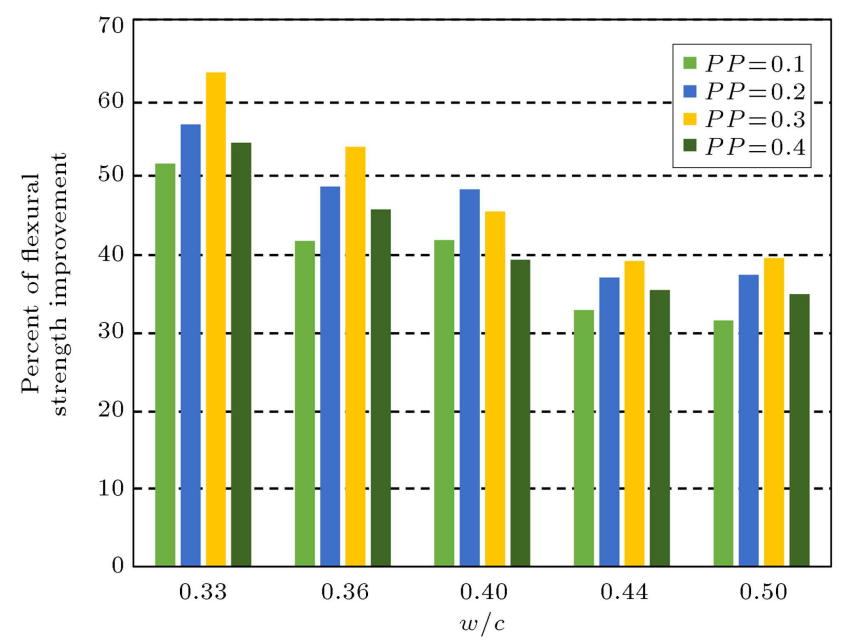

Figure 3. The percentage of improvement in the flexural strength of the fibers for different ratios of water to cement. tensile strength has improved by $11.96 \%, 16.13 \%$, and $17.68 \%$, respectively, compared to non-fibrous samples (Figure 6).

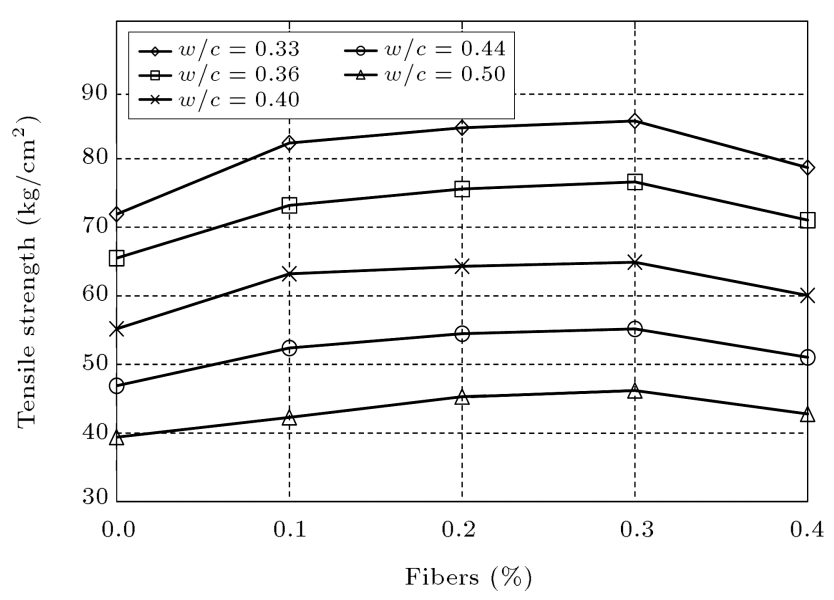

Figure 4. Tensile strength of the fiber-based samples for different water to cement ratios.

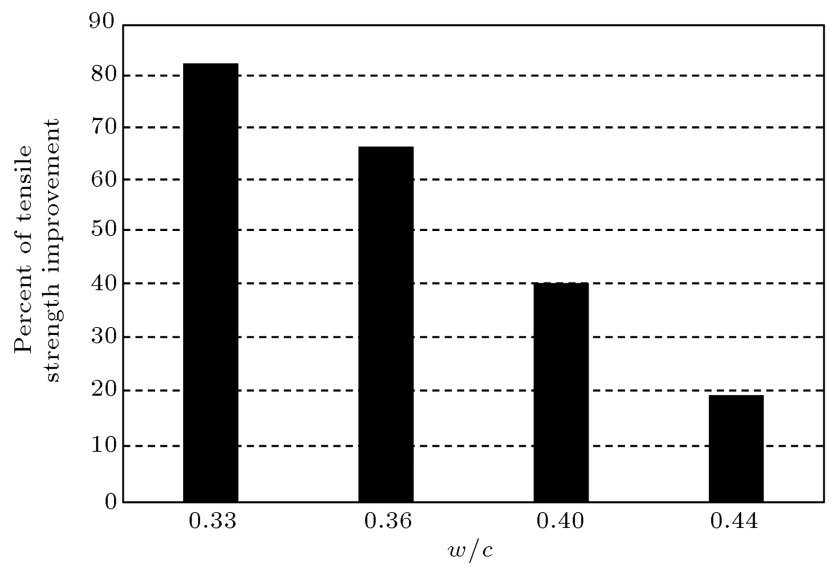

Figure 5. The percentage of improvement in tensile strength without fiber for water to cement ratio of 0.50 .

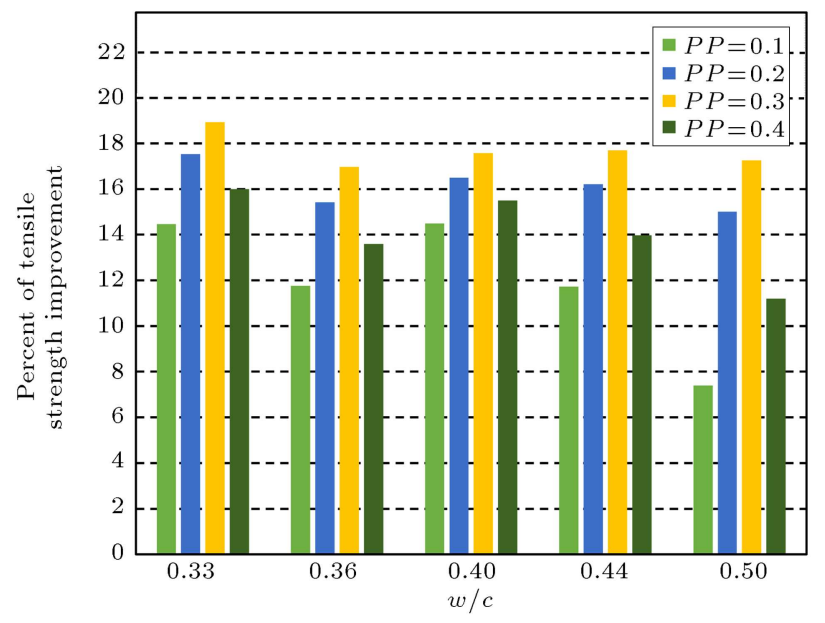

Figure 6. The percentage of improvement in the tensile strength of the fibers for different ratios of water. 


\section{Analysis of the abrasion strength test results}

Figures 7 and 8 show the abrasion resistance of reinforced concrete. One can see the changes in the abrasion resistance of the samples by the fiber addition. Increasing the fiber content up to $0.2 \%$ can increase the abrasion resistance. However, by increasing the fiber content to more than $0.2 \%$, the abrasion resistance of the non-fibrous samples decreases, since the fiber will make the samples more porous. Figure 9 illustrates that by reducing the water to cement ratio from 0.5 to 0.33 , the abrasion resistance of non-fibrous concrete samples has improved by $46 \%$. By adding $0.1,0.2$, and $0.3 \%$ of the fiber to the concrete samples for the water to cement ratio of $0.33 \%$, the abrasion resistance improves by $14,25.45$, and $9.68 \%$, respectively, compared to the non-fibrous samples (Figure 10). As the water to cement ratio increases from 0.33 to 0.50 , the slope of the depth of the abrasion curve decreases gradually. This is related to the two-phase nature of concrete in abrasion (phase of mortar and phase of aggregates).

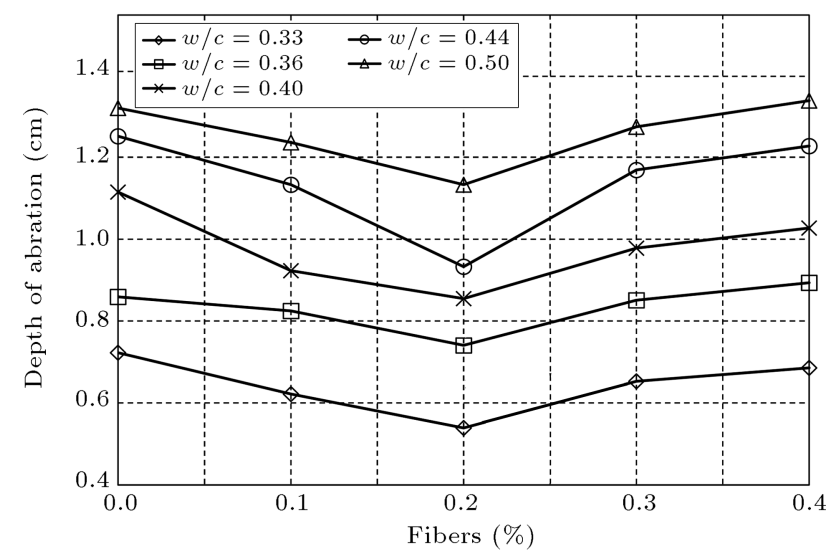

Figure 7. Depth of abrasion variation of fiber-based samples for different water to cement ratios.

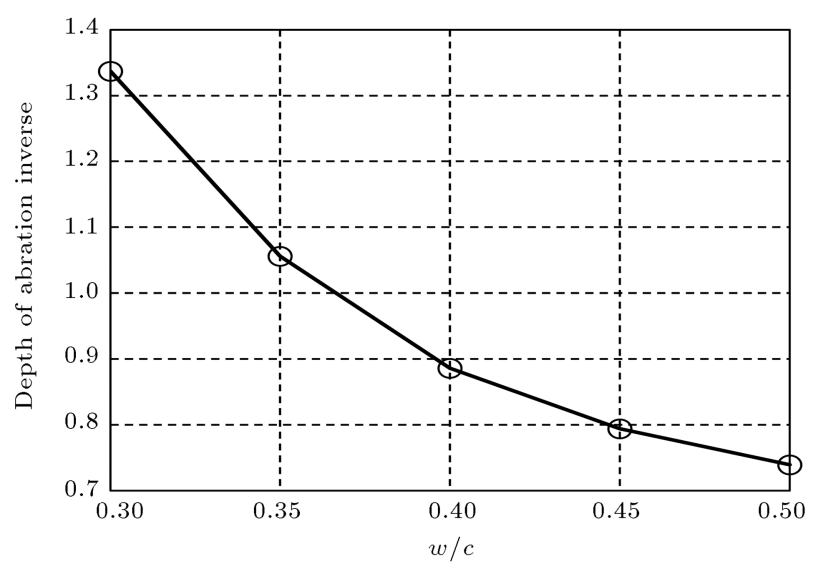

Figure 8. Abrasion strength variation of non-fibrous samples for different water to cement ratios.

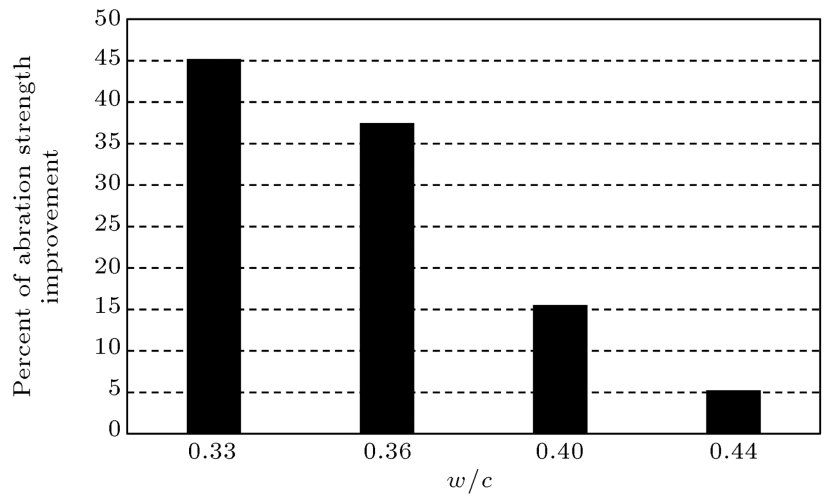

Figure 9. The percentage of improvement in abrasion strength of non-fibrous samples for the water to cement ratio of 0.50 .

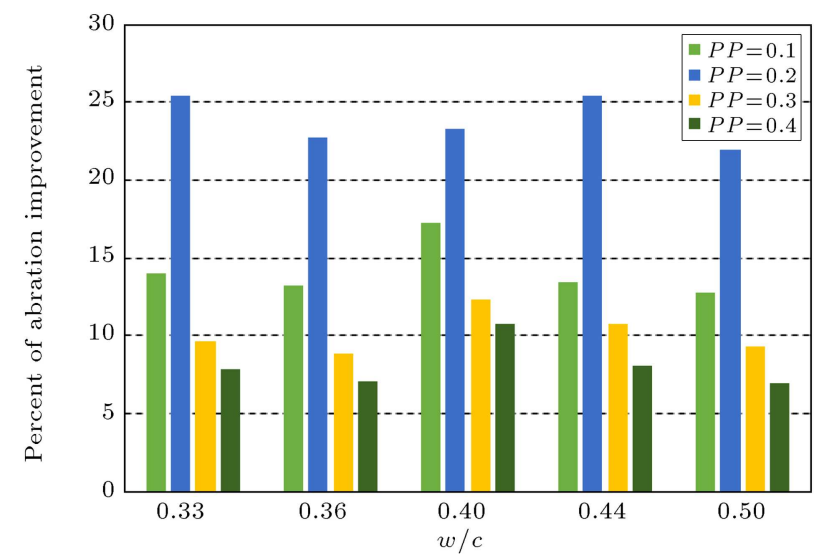

Figure 10. The percentage of improvement in the abrasion strength of the fiber-based samples for different ratios of water to cement.

As the ratio of water to cement increases, the abrasion strength of the mortar phase decreases; however, the abrasion strength of the concrete will tend towards the abrasion strength of the aggregates.

\section{Analysis of the hydraulic conductivity coefficient and porosity of concrete results}

The analysis of Figures 11 to 13 shows the hydraulic conductivity coefficient, which is changed by the addition of fibers. Using fibers up to $0.2 \%$ reduces the depth of water penetration and hydraulic conductivity. Nevertheless, these values increase by increasing fibers to more than $0.2 \%$. The reason for this behavior of most porous samples is due to the addition of more fiber content. According to Figure 11, it is obvious that by decreasing the ratio of water to cement from 0.50 to 0.33 , the hydraulic conductivity of non-fibrous concrete samples decreases from $43.03 \times 10^{-15} \mathrm{~m} / \mathrm{s}$ to $6.3 \times 10^{-15} \mathrm{~m} / \mathrm{s}$. In other words, the hydraulic conductivity coefficient of samples has improved by about $85.36 \%$. Figure 13 displays that in the water 
to cement ratio of 0.33 , the hydraulic conductivity coefficient of $0.1,0.2$, and $0.3 \%$ of the fibers improved by $25.08,41.43$, and $17.9 \%$, respectively. In addition,

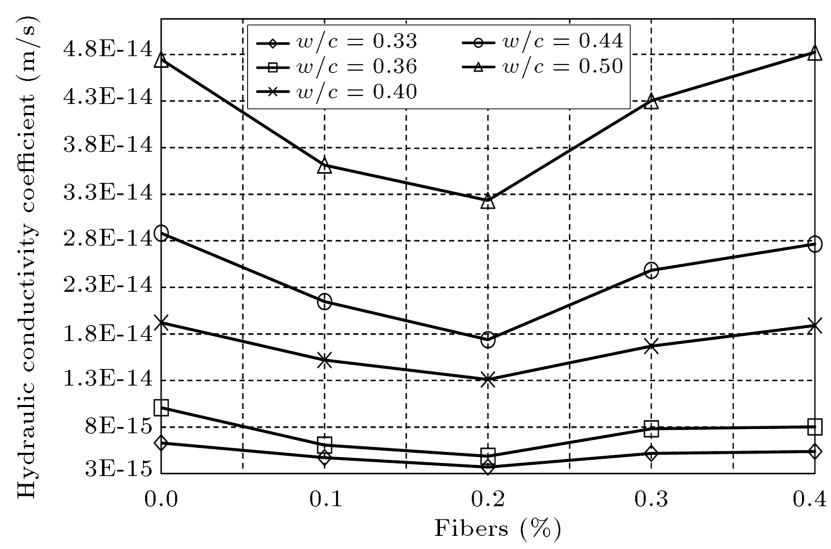

Figure 11. Hydraulic conductivity coefficient variation of fiber-based samples for different water to cement ratios.

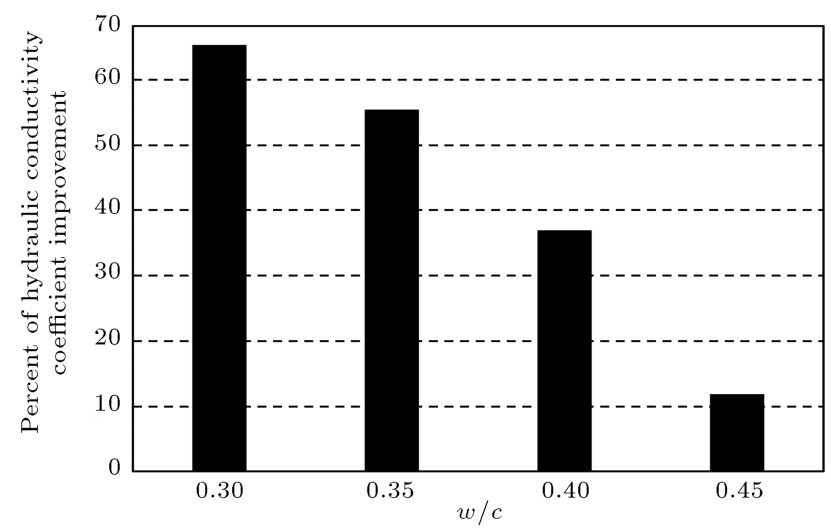

Figure 12. The percentage of improvement in hydraulic conductivity coefficient of non-fibrous samples for the water to cement ratio of 0.50 .

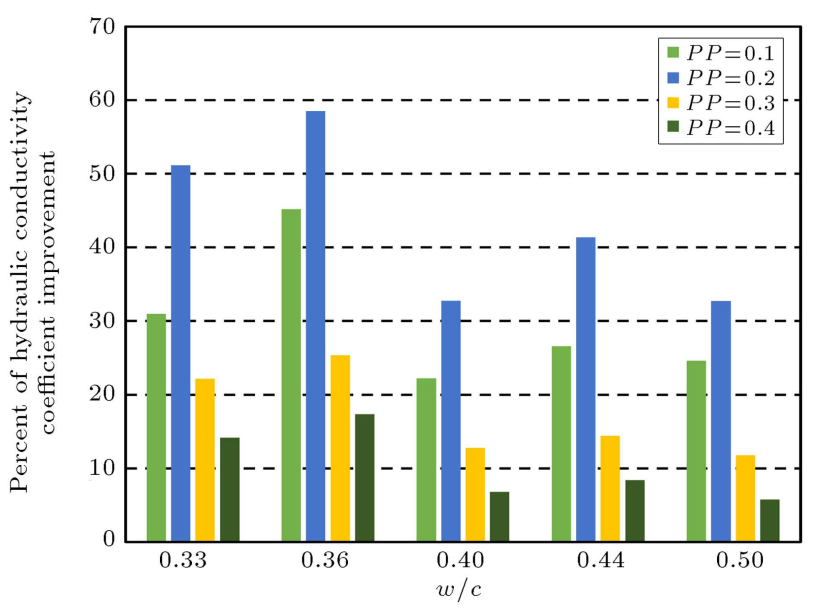

Figure 13. The percentage of improvement in hydraulic conductivity coefficient of the fiber-based samples for different ratios of water to cement. by reducing the ratio of water to cement from 0.50 to 0.33 , the concrete porosity decreases from 14.4 to $13.5 \%$ (Figure 14).

\section{Analysis of the compressive strength test results}

Figures 15 to 17 show the results of compressive strength test and the percentage of improved compressive strength of fibrous samples (0.1, 0.2 and 0.3 ), compared with non-fibrous specimens. Investigations of the compressive strength of the fiber-reinforced concrete show that the adhesive strength changes with the addition of the fibers. Using $0.1 \%$ fiber with a constant water to cement ratio of 0.33 causes a relative increase in compressive strength on the 7 th, 28 th, and 90 th days. By increasing fibers to more than $0.1 \%$, the compressive strength decreases. The reason for this behavior is that when the amount of fiber in concrete increases by a certain amount, compressive strength values are reduced due to poor fiber dispersion.

According to Figure 16, by reducing the ratio of water to cement from 0.50 to 0.33 , the compressive

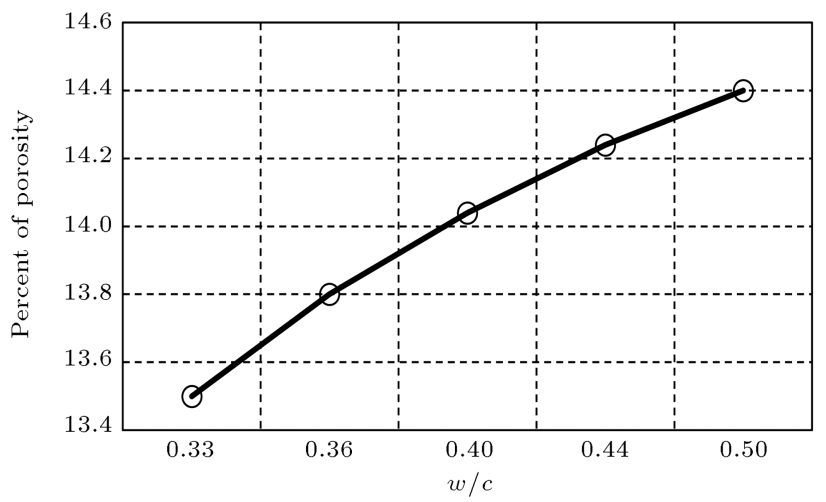

Figure 14. Percentage of concrete porosity variation for different water to cement ratios.

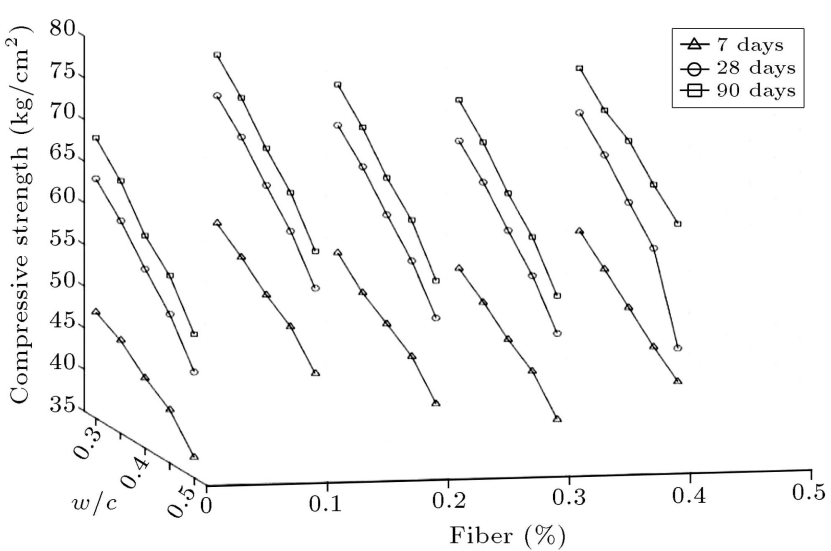

Figure 15. 7-, 28-, and 90-day compressive strength variations of fiber-based samples for different water to cement ratios and fiber percentages. 
strength of non-fibrous concrete samples at the age of 7,28 , and 90 days of concrete has improved by 27.92 , 33.04 , and $31.88 \%$, respectively. Figure 17 illustrates that by adding fiber at $0.1,0.2$, and $0.3 \%$, compared to non-fibrous samples, the compressive strength of the samples on the 7 th, 28 th, and 90 th days has improved by $(21.42,15.29$, and $13.44 \%),(13.52,8.47$, and $35.8 \%)$, and (8.42, 5.9, and 5.71), respectively.

\section{Microstructures}

Studying the microstructure of cement paste and concrete by Scanning Electron Microscope (SEM) images has revealed a new horizon in the concrete technology

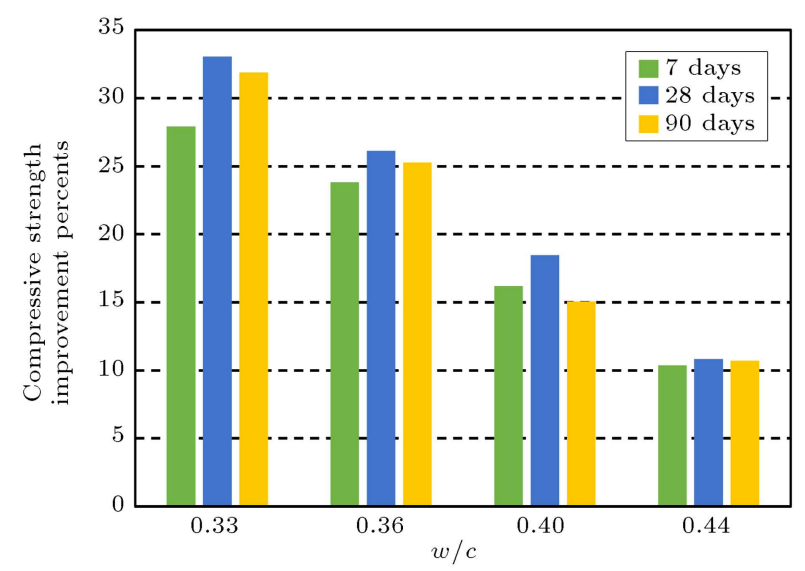

Figure 16. The percentage of improvement in compressive strength of non-fibrous samples for the water to cement ratio of 0.50 . in recent years. Concrete characteristics including specific gravity and all kinds of chemical reactions and hydration created in the initial and final setting processes of concrete have a direct and close relationship with the concrete microscopic structure. Therefore, this study investigates the microstructure of concrete in the process of cement hydration and the placement state of concrete besides various admixtures: materials are added to concrete, including various types of fibers and pozzolans using Scanning Electron Microscope (SEM), which are very important.

In this investigation, polypropylene fibers and nano-silica were added to concrete, and a detailed investigation into their arrangement in the concrete structure was carried out.

Scanning Electron Microscope (SEM) was used for studying three types of cement pastes including a control mix design, a mix design containing $2 \%$ (polypropylene) fibers, 3\% nano-silica, a mix design containing $2 \%$ (polypropylene) fibers, and $4 \%$ nanosilica, whose hydration reaction stopped using acetone at the age of 7 days. The taken images (by scanning electron microscope) are divided into two groups: the fracture surface and the modeled transition zone (region) between the paste and the fibers.

The results of tests and microscopic photos and their comparison with the voucher sample (Figure 18) show that the addition of nano-silica to concrete $(3 \%$ by weight of cement) reduces the volume of cavities and creates a smooth surface with less porosity. In addition, adding polypropylene fibers ( $2 \%$ by volume) improved the concrete integrity (Figure 19). The

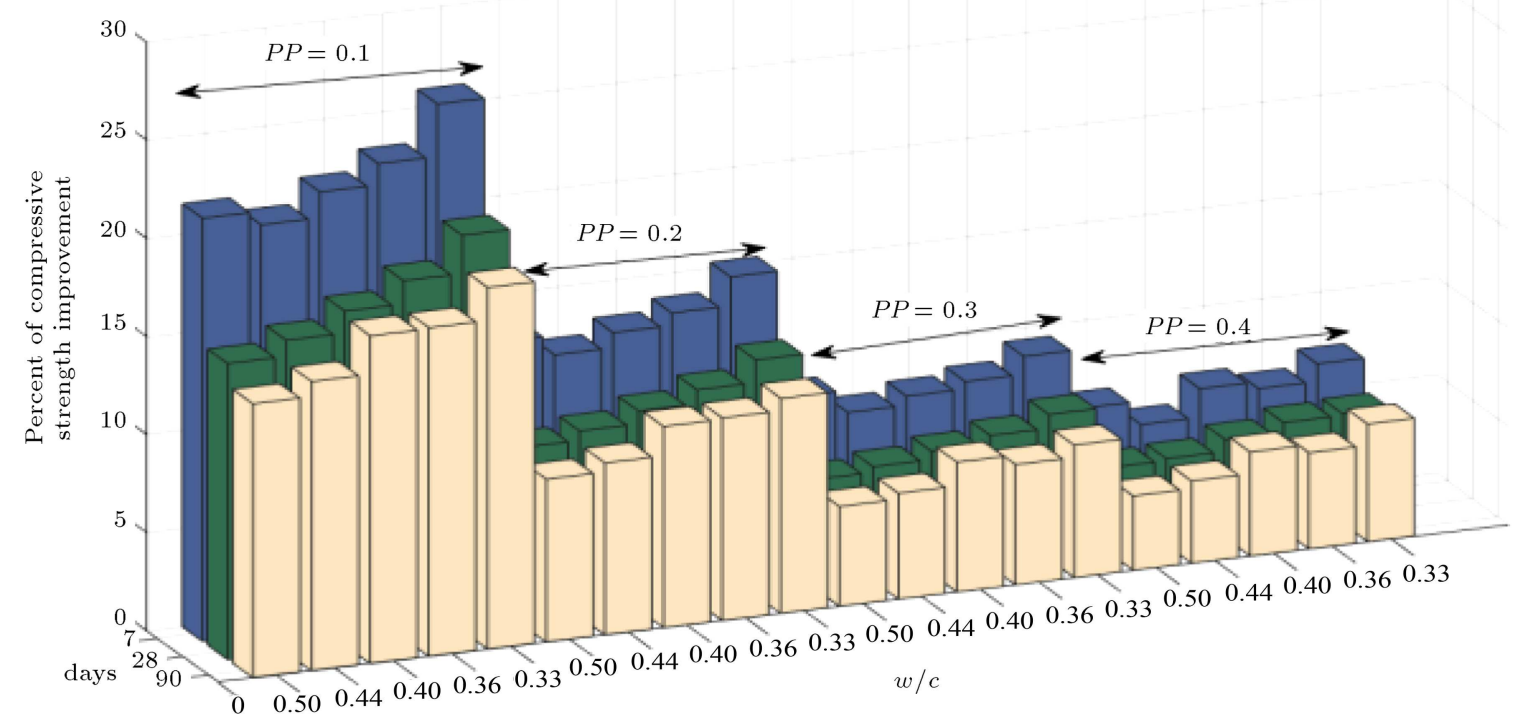

Figure 17. 7-, 28-, and 90-day compressive strength improvement percentage of fiber-based samples for different water to cement ratios and fiber percentages. 


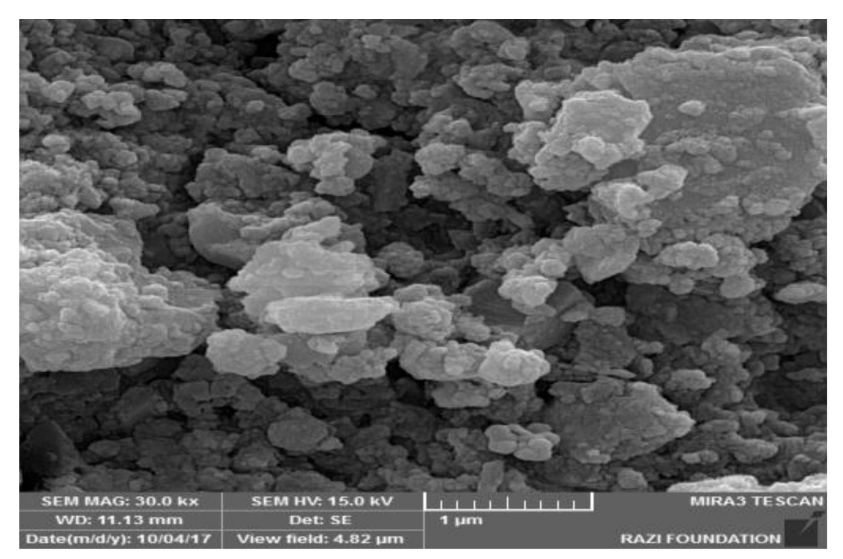

Figure 18. The microscopic photo of referenced concrete specimen.

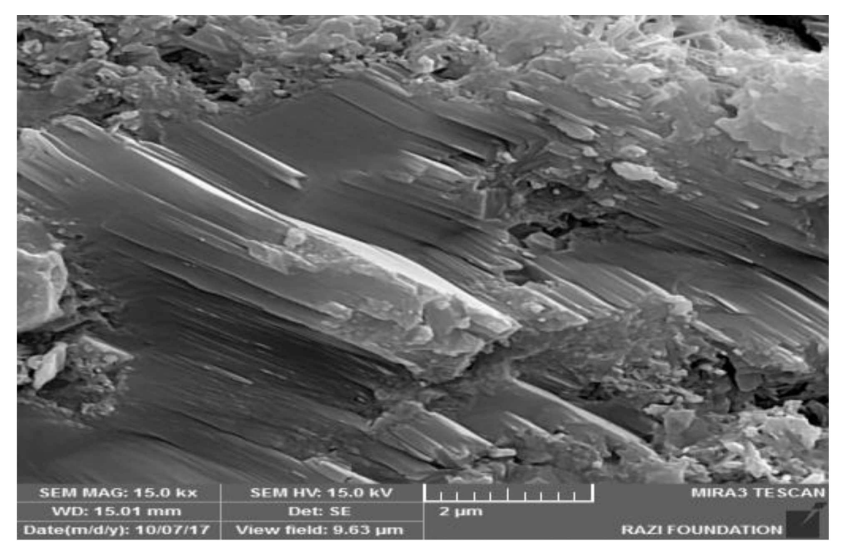

Figure 19. The microscopic photo of concrete specimen containing (including) the optimum value (amount) of polypropylene fibers.

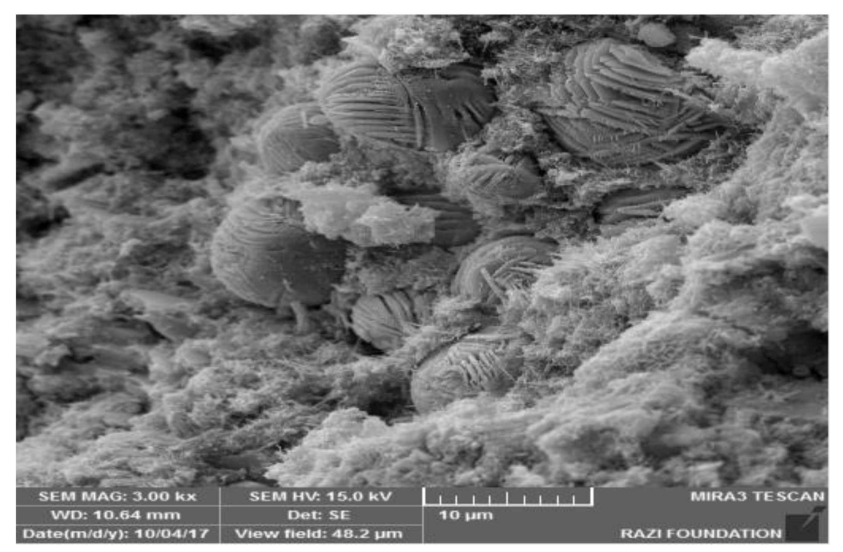

Figure 20. The microscopic photo of conglobation phenomenon of concrete specimen due to unsuitable distribution of fibers and using more than the optimum value (amount) of polypropylene fibers.

difference between the density of control sample and fiber-containing sample is clear.

According to Figure 20, using more than the optimum value ( $0.4 \%$ by volume) of polypropylene fibers results in the conglobation phenomenon due to

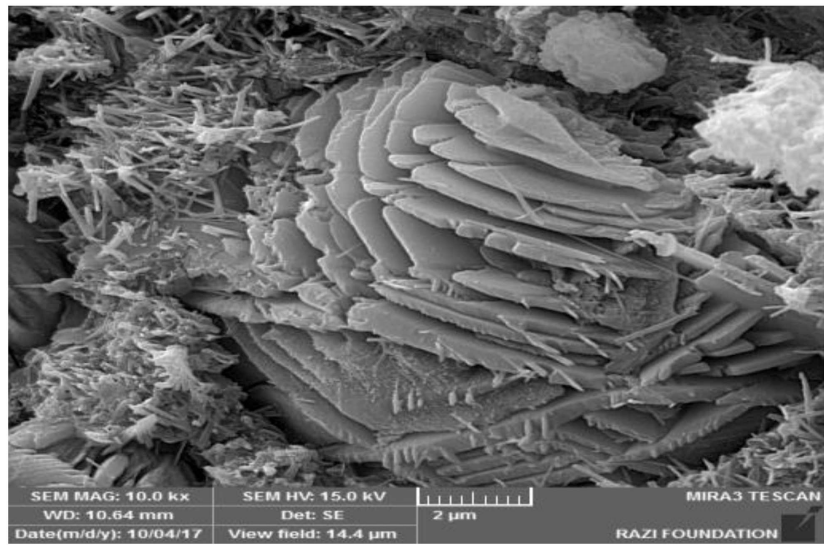

Figure 21. The microscopic photo of agglomeration phenomenon of concrete specimen due to unsuitable distribution and the use of more than the optimum amount of nano-silica.

unsuitable distribution of fibers. This phenomenon practically causes the fibers to be ineffective in improving the mechanical properties of concrete.

In addition, according to Figure 21, when the amount of nano-silica addition is more than the optimum value ( $4 \%$ by weight of cement), the particles of nano-silica stick to each other due to a physical reaction, and they become unstable lumps, thus weakening the concrete structure.

\section{Conclusion}

In this paper, with an overview of the history and advantages of using nano-silica concrete with polypropylene fibers, the mechanical properties of concrete samples (e.g., compressive, flexural, tensile, and abrasion strengths, permeability, and porosity) were evaluated. The main and most important results are drawn, as presented below:

- In the ratio of $0.1 \%$ fiber and $3 \%$ nano-silica, an optimal compressive strength state occurs and continues until the end of the experiments. The reason for this is the inappropriate diffusion of fibers and the reduction of concrete slump, because the superlubricant is constant during the test; thus, it is better to increase the nano-silica in order to achieve higher resistance by increasing the fiber;

- In the ratio of $0.2 \%$ fiber and $3 \%$ nano-silica, an optimal abrasion strength condition takes place. By increasing the fiber content to more than $0.2 \%$, the abrasion strength is reduced due to the porosity of the samples;

- Fibers of $0.3 \%$ produced a significant increase in the tensile strength, which is more obvious by the increase of fiber content. The presence of fibers in concrete, which is a brittle body, improves the 
samples' ductility and improves tensile strength of concrete;

- In the ratio of $0.2 \%$ fiber and $3 \%$ nano-silica, an optimal state occurs at a depth of water penetration and hydraulic conductivity;

- The reason for reducing the permeability in the presence of fibers is due to the placement of fibers between the porous bonding pathways and their blocking, resulting in the removal of the capillary property and the permeability decreases;

- In the ratio of $0.3 \%$ fiber and $3 \%$ nano-silica, an optimum state of flexural strength occurs. By adding fibers more than $0.3 \%$, flexural strength decreases, compared to non-fibrous samples. In the presence of samples of more than $0.3 \%$ fiber, the flexural strength decreases due to the lack of suitable fibers; the balling phenomenon is evident here;

- It is clear based on the SEM images of the fracture surfaces of hardened paste that the presence of nano-silica and polypropylene fibers at optimum levels has improved the density of the cement paste structure, and the paste structure has clearly higher density and uniformity in the presence of these two materials.

\section{References}

1. Farnam, Y., Shekarchi, M., and Mirdamadi, A. "Experimental investigation of impact behavior of high strength fiber reinforced concrete panels", 2nd Int. Symp. on Ultra High Performance Concrete., Kassel, Germany, pp. 751-758 (2008).

2. Huang, W.H. "Properties of cement-fly ash grout admixed with bentonite, silica fume, or organic fiber", Cem. Concr. Res., 27(3), pp. 395-406 (1997).

3. Huang, W.H. "Improving the properties of cementfly ash grout using fiber and superplasticizer", Cem. Concr. Res., 31(7), pp. 1033-1041 (2001).

4. Morgan, D.R., Mcaskill, N., Carette, G.G., and Malhotra, V.M. "Evaluation of polypropylene fiber reinforced high-volume fly ash shotcrete", ACI Mater J., 89(2), pp. 169-177 (1992).

5. Mugume, R.B. and Takashi, H. "Effect of fibre type and geometry on maximum pore pressures in fibrereinforced high strength concrete at elevated temperatures", Cem. Concr. Res., 42, pp. 459-466 (2012).

6. Bangi, M.R. and Horiguchi, T. "Pore pressure development in hybrid fibre-reinforced high strength concrete at elevated temperatures", Cem. Concr. Res., 41, pp. 1150-1156 (2011).

7. Saka, T. "Spalling potential of fire exposed structural concrete", Proc. of the 1st Int. Workshop on Concr. Spalling due to Fire Expos., Leipzig, Germany, pp. 3-5 (2009).
8. Khoury, G.A. "Polypropylene fibres in heated concrete, Part 2: Pressure relief mechanisms and modelling criteria", Mag. Concr. Res., 60, pp. 189-204 (2008).

9. Olivito, R.S. and Zuccarello, F.A. "An experimental study on the tensile strength of steel fiber reinforced concrete", Composites Part B: Eng., 41(3), pp. 246255 (2010).

10. Zhang, P. and Li, Q.-F. "Combined effect of silica fume and polypropylene fiberon drying shrinkage properties of concrete composites containing fly ash", Scientia Iranica, 20(5), pp. 1372-1380 (2013).

11. Kalifa, P., Chéné, G., and Gallé, C. "High-temperature behaviour of HPC with polypropylene fibres - from spalling to microstructure", Cem. Concr. Res., 31, pp. 1487-1499 (2001).

12. Noumowé, A. "Mechanical properties and microstructure of high strength concrete containing polypropylene fibres exposed to temperatures up to $200^{\circ} \mathrm{C}$ ", Cem. Concr. Res., 35, pp. 2192-2198 (2005).

13. Zeiml, M., Leithner, D., Lackner, R., and Herbert, A.M. "How do polypropylene fibers improve the spalling behavior of in-situ concrete?", Cem. Concr. Res., 36, pp. 929-942 (2006).

14. Bilodeau, A., Kodur, V.K.R., and Hoff, G.C. "Optimization of the type and amount of polypropylene fibers for preventing the spalling of lightweight concrete subjected to hydrocarbon fire", Cem. Concr. Compos., 26, pp. 163-174 (2004).

15. Ozawa, M. and Morimoto, H. "Effects of various fibres on high-temperature spalling in high-performance concrete", Constr. Build. Mater., 71, pp. 83-92 (2014).

16. Kodur, V. "Properties of concrete at elevated temperatures", ISRN Civ. Eng., 2014, pp. 1-15 (2014).

17. Consoli, N.C., Vendruscolo, M.A., Fonini, A., and Rosa, F.D. "Fiber reinforcement effects on sand considering a wide cementation range", Geotext. Geomemb., 27(3), pp. 196-203 (2009).

18. Unterweger, C., Brüggemann, O., and Fürst, C. "Effects of different fibers on the properties of short-fiberreinforced polypropylene composites", Combust. Sci. Technol., 13, pp. 49-55 (2014a).

19. Unterweger, C., Brüggemann, O., and Fürst, C. "Synthetic fibers and thermoplastic short-fiber-reinforced polymers: properties and characterization", Polym. Compos., 35, pp. 227-236 (2014b).

20. Kayali, O., Haque, M.N., and Zho, B. "Some characteristics of high strength fibre reinforced lightweight aggregate concrete", Cem. Concr. Compos., 25, pp. 207-213 (2003).

21. Nili, M. and Afroughsabet, V. "Combined effect of silica fume and steel fibers on the impact resistance and mechanical properties of concrete", Int. J. Impact Eng., 37(8), pp. 879-886 (2010).

22. Gonen, T. and Yazicioglu, S. "The influence of compaction pores on sorptivity and carbonation of concrete", Constr. Build. Mater., 21(5), pp. 1040-1045 (2007). 
23. Basheer, L., Basheer, P.A.M., and Long, A.E. "Influence of meso-macro aggregate on the permeation, durability and the microstructure characteristics of ordinary Portland cement concrete", Constr. Build. Mater., 19(9), pp. 682-690 (2005).

24. Kumara, R. and Bhattacharjee, B. "Porosity, pore size distribution and in situ strength of concrete", Cem. Concr. Res., 33(1), pp. 155-164 (2003).

25. Tijani, A.I., Yang, J., and Dirar, S. "Enhancing the performance of recycled aggregate concrete with microsilica", Int. J. Struct. Civil Eng. Res., 4(4), pp. 347-353 (2015).

26. Maslennikov, S., Dmitrienko, V., Kokunko, I., and Dmitrienko, N. "Investigating the micro silica effect on the concrete strength", Matec Web of Conf., 106, pp. 25-30 (2017).

27. Subramanian, E.S., Arunkumar, P., and Arul, N. "Strength and durability properties of self-compacting concrete with micro silica and nano-silica", Int. Res. J. of Eng. and Tech., 04(01), pp. 146-149 (2017).

28. Khanzadi, M., Tadayon, H., and Sepehri, M. "Influence of nano-silica particles on mechanical properties and permeability of concrete", 2nd Int. Conf. on Sust. Const. Materials and Tech., Ancona, Italy, pp. 28-30 (2010).

29. Yermak, N., Pliya, P., Beaucour, A.-L., Simon, A., and Noumowe, A. "Influence of steel and/or polypropylene fibers on the behavior of concrete at high temperature: Spalling, transfer and mechanical properties", Const. Build. Mat., 132, pp. 240-250 (2017).

30. ASTM C1018 "Standard test method for flexural toughness and first crack strength of fiber reinforced concrete (using beam with third point loading)".

31. ASTM C496 "Standard test method for tensile strength of concrete".
32. ASTM C1920-5 "Standard test method for permeability and hydraulic conductivity of concrete".

33. ASTM C1084 "Standard test method for portlandcement content of hardened hydraulic-cement concrete.

\section{Biographies}

Kamal Rahmani received his BS degree in Civil Engineering from Islamic Azad University and his MS degree in Civil Engineering from Islamic Azad University of Mahabad and Science and Research Branches in 1998 and 2002, respectively. $\mathrm{He}$ is currently a PhD degree student at Science and Research Branch of Tehran-Islamic Azad University. His research interests include hydraulic structures, concrete technology, and structural engineering. He has presented and published several papers in various national and international conferences and scientific journals.

Mohsen Ghaemian is a Professor at the Civil Engineering Department of Sharif University of Technology. His current activity concerns concrete technology, dynamic responses of gravity and arch dams. Dam reservoir interaction effects, seismic response of dams due to non-uniform excitations, and nonlinear behavior of concrete dams have been his research interests in these recent years.

Seyed Abbas Hosseini obtained his BS in Civil Engineering, MS in Hydraulic Structure, and $\mathrm{PhD}$ degree in Water Engineering from Sharif University of Technology. He is currently an Assistant Professor of Technical \& Engineering Department at Islamic Azad University, Science and Research Branch, Tehran, Iran. His research interests include experimental and numerical modeling of incompressible flow, sediment transport, and scouring in hydraulic structures. 